\title{
Application of Functionalized SWCNTs for Increase of Degradation Resistance of Acrylic Paint for Cars
}

\author{
Osiel Lucas Flores, Oxana V. Kharissova, Ubaldo Ortiz Méndez, Héctor Leija Gutiérrez, \\ Edgar de Casas Ortiz, and Boris I. Kharisov
}

Postgraduate Division, Physico-Mathematics Faculty, Autonomous University of Nuevo Leon, 66450 San Nicolas de los Garza, NL, Mexico

Correspondence should be addressed to Oxana V. Kharissova; okhariss@mail.ru

Received 15 June 2012; Accepted 5 August 2012

Academic Editor: Romdhane Karoui

Copyright (C) 2013 Osiel Lucas Flores et al. This is an open access article distributed under the Creative Commons Attribution License, which permits unrestricted use, distribution, and reproduction in any medium, provided the original work is properly cited.

Physical properties of automotive acrylic paint are improved by incorporation of three different types of carbon nanotubes: singlewall carbon nanotubes (SWCNTs), OH-functionalized single-wall carbon nanotubes (OH-SWCNTs), and aniline-functionalized single-wall carbon nanotubes (aniline-SWCNTs). The formed composites are studied by electron miscroscopy methods and Raman spectrometry. It is found that the acrylic paints with addition of OH-SWCNTs and aniline-SWCNTs show better quality for their applications. In particular, the resistance against degradation by electron beam increased in $\sim 500 \%$.

\section{Introduction}

Due to a wide variety of mechanical, thermal, and electric properties of the carbon nanotubes (CNTs), there are a host of their applications in the nanotechnology fields, described in special technical reports [1], books [2-5], reviews [68], and original reports [9-12]. Frequently, an addition of small quantities of CNTs into matrices of various materials frequently improve their properties $[13,14]$. In this work, we studied the changes in the automotive acrylic paint caused by the incorporation of CNTs, in particular improvement of mechanical resistance and degradation.

\section{Experimental}

2.1. Materials and Equipment. The single-walled carbon nanotubes, SWCNTs (length 10-20 $\mu \mathrm{m}$ ) and OH-SWCNTs, were purchased with NanoAmorphous Materials (Houston, TX), and used as supplied. The acrylic paint Flex Acrylic (components: acrylic resin, toluene, xylene, and other aromatic compounds) was used as supplied. Ultrasonic cleaner was used for homogenization purposes (model Branson 200, 120 $\mathrm{V}$, frequency $50 / 60 \mathrm{~Hz}$ ). Other equipments are as follows: dry oven SL SHELLAB, M: 1400E; TEM (transmission electron microscopy equipment): JEOL JEM 2010 FE-TEM; SEM (scanning electron microscopy equipment): HITACHI S5500 (University of Texas at Arlington), Raman spectrometer: HORIBA JOBIN YVON, iHR 320, Laser RMS-320 Raman System; AFM (atomic force microscopy equipment): model Q-Scope 250 from QUESANT.

2.2. CNTs Functionalization with Anilines. The functionalized carbon nanotubes were prepared as follows. Carboxyl groups formation was reached by addition of commercial SWCNTs $(0.05 \mathrm{~g})$ to oleum $(30 \mathrm{~mL})$ in a Shlenk tube for $12 \mathrm{~h}$ at permanent stirring at r.t. under nitrogen atmosphere [15, 16]. Then, the corresponding aniline (4-aminopyridine $1.1 \mathrm{~g}$, 5 -aminoisophthalic acid $2.43 \mathrm{~g}$, $p$-anisidine $1.65 \mathrm{~g}$ ) (Figure 1) was added, stirring the mixture for $30 \mathrm{~min}$ under nitrogen at r.t. sodium sulfite $(0.92 \mathrm{~g})$ and $t$-butyl peroxide $(1.2 \mathrm{~mL})$ were added to generate aryl-diazonium salt.

In order to achieve an interchange of formed $-\mathrm{COOH}$ groups by diazonium groups $(-N+\equiv N)$ (Figure 2), the temperature was increased to $80^{\circ} \mathrm{C}$ using an oil bath and maintained for $3 \mathrm{~h}$ at permanent stirring under nitrogen flow. Then, the reaction path was interrupted by cooling in ice.

In order to get a solid product, the filtration equipment, shown in Figure 3, was used. The filter was a polycarbonate 
TABLE 1: Nomenclature of SWCNTs-acrylic paint composites, used in the present research.

\begin{tabular}{|c|c|c|c|c|c|}
\hline \multicolumn{6}{|c|}{ Nomenclature paint sample } \\
\hline \multicolumn{2}{|c|}{ With SWCNT's-OH } & \multicolumn{2}{|c|}{ With SWCNT's-anisidine } & \multicolumn{2}{|c|}{ With SWCNT's } \\
\hline Sample & wt.\% of nanotubes & Sample & wt.\% of nanotubes & Sample & wt.\% of nanotubes \\
\hline P1SWOH1 & 0.038 & P1SWFC1 & 0.038 & P1SW1 & 0.038 \\
\hline P1SWOH2 & 0.077 & P1SWFC2 & 0.077 & P1SW2 & 0.077 \\
\hline P1SWOH3 & 0.200 & P1SWFC3 & 0.200 & P1SW3 & 0.200 \\
\hline P1SWOH4 & 0.038 & P1SWFC4 & 0.038 & P1SW4 & 0.038 \\
\hline P1SWOH5 & 0.077 & P1SWFC5 & 0.077 & P1SW5 & 0.077 \\
\hline
\end{tabular}<smiles>Nc1ccncc1</smiles><smiles>Nc1cc(C(=O)O)cc(C(=O)O)c1</smiles><smiles>COc1ccc(N)cc1</smiles>

FIgURE 1: Anilines used in the functionalization (4-aminopyridine, 5-aminoisophthalic acid, $p$-anisidine).
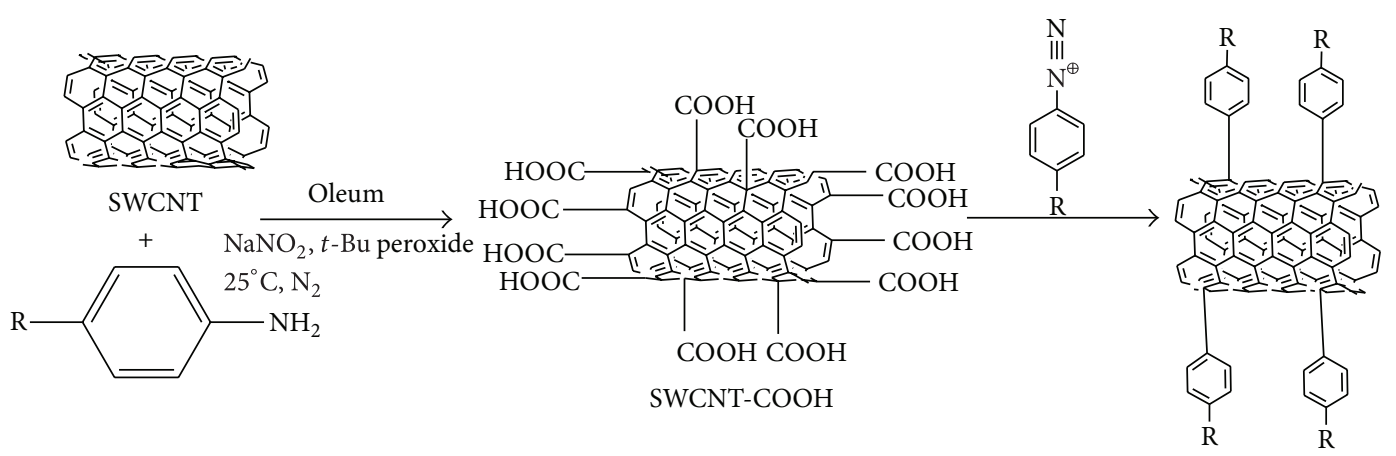

FIGURE 2: Synthesis of functionalized carbon nanotubes.

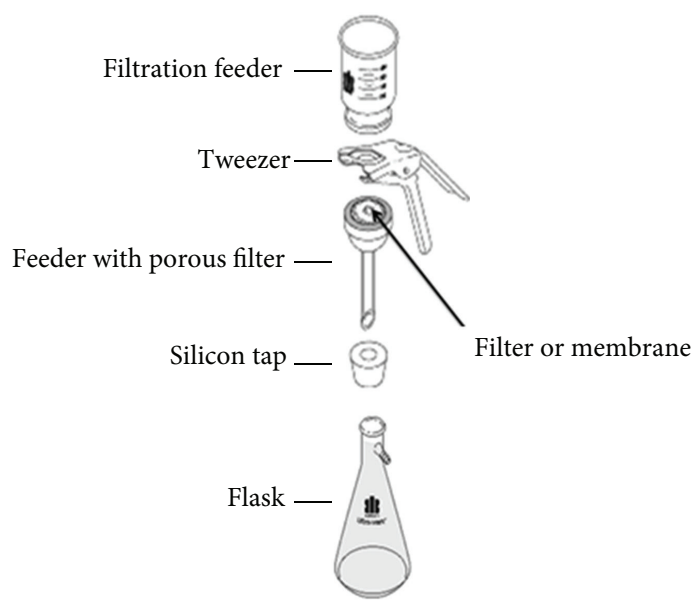

(a)

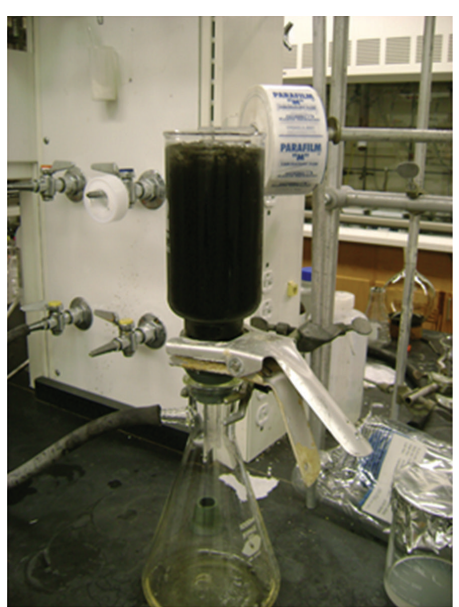

(b)

FIgURE 3: Filtration equipment. 


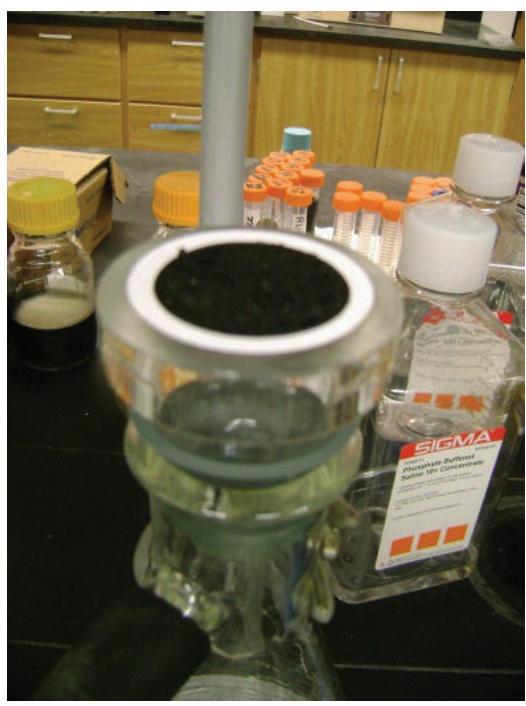

FIGURE 4: The formed film of functionalized carbon nanotubes.

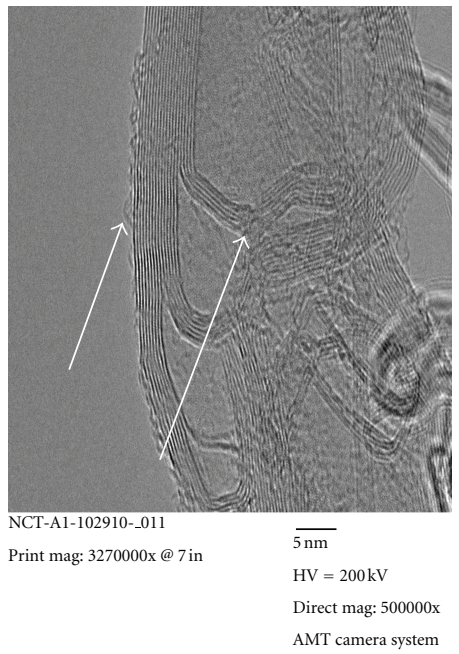

(a)

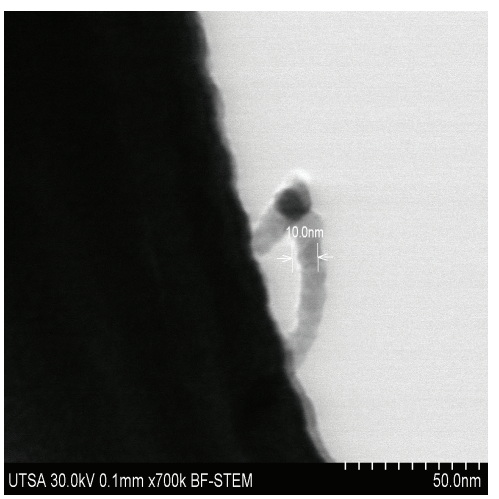

(b)

Figure 5: (a) TEM image of 4-aminopyridine-SWCNTs, (b) SEM image of the product.
TABLE 2: ANOVA for 3 factors (particle, concentration, and process type). ${ }^{*}$

\begin{tabular}{lcccc}
\hline Sample & $\begin{array}{c}\text { Nanoparticle used } \\
\text { wt.\% of } \\
\text { Nanoparticles }\end{array}$ & SWCNTs & $\begin{array}{c}\text { OH- } \\
\text { SWCNTs }\end{array}$ & $\begin{array}{c}\text { Anisidine- } \\
\text { SWCNTs }\end{array}$ \\
\hline 1 & 0.038 & P1SW1 & P1SWOH1 & P1SWFC1 \\
2 & 0.077 & P1SW2 & P1SWOH2 & P1SWFC2 \\
3 & 0.20 & P1SW3 & P1SWOH3 & P1SWFC3 \\
4 & 0.38 & P1SW4 & P1SWOH4 & P1SWFC4 \\
5 & 0.77 & P1SW5 & P1SWOH5 & P1SWFC5 \\
\hline
\end{tabular}

*Drying at $200^{\circ} \mathrm{C}$.

TABLE 3: Thickness of the final layer.

\begin{tabular}{lccccc}
\hline Sample & $(\mu \mathrm{m})$ & Sample & $(\mu \mathrm{m})$ & Sample & $(\mu \mathrm{m})$ \\
\hline P1SWOH1 & 108.41 & P1SWFC1 & 104.48 & P1SW1 & 111.20 \\
P1SWOH2 & 83.44 & P1SWFC2 & 108.08 & P1SW2 & 136.63 \\
P1SWOH3 & 91.52 & P1SWFC3 & 122.94 & P1SW3 & 139.25 \\
P1SWOH4 & 76.28 & P1SWFC4 & 109.12 & P1SW4 & 160.88 \\
P1SWOH5 & 73.45 & P1SWFC5 & 118.11 & P1SW5 & 157.48 \\
\hline
\end{tabular}

TABle 4: Thermal dissipation $\left({ }^{\circ} \mathrm{C} / \mathrm{min}\right)$.

\begin{tabular}{lccccc}
\hline Sample & $\left({ }^{\circ} \mathrm{C} / \mathrm{min}\right)$ & Sample & $\left({ }^{\circ} \mathrm{C} / \mathrm{min}\right)$ & Sample & $\left({ }^{\circ} \mathrm{C} / \mathrm{min}\right)$ \\
\hline P1SWOH1 & 24.24 & P1SWFC1 & 24.6 & P1SW1 & 25.87 \\
P1SWOH2 & 40.96 & P1SWFC2 & 33.69 & P1SW2 & 25 \\
P1SWOH3 & 46.4 & P1SWFC3 & 48.43 & P1SW3 & 28.74 \\
P1SWOH4 & 51.66 & P1SWFC4 & 44.28 & P1SW4 & 28.18 \\
P1SWOH5 & 48.43 & P1SWFC5 & 46.4 & P1SW5 & 27.19
\end{tabular}

TABle 5: Degradation of samples via electron flow of $30 \mathrm{kV}$.

\begin{tabular}{lcc}
\hline & Sample & Time (s) \\
\hline 1 & Target & 9 \\
2 & P1SW3 & 45 \\
3 & P1SWOH4 & 51 \\
4 & P1SWFC4 & 46 \\
\hline
\end{tabular}

membrane of $0.45 \mu \mathrm{m}$ thickness. As a result, a black thin film of functionalized carbon nanotubes was obtained (Figure 4). A series of 15-min. washing procedures with distilled water, N,N-dimethylformamide and acetone was applied in the sonication equipment and further filtration each time. The final product was dried in an oven at $200^{\circ} \mathrm{C}$ for $5 \mathrm{~h}$. The functionalized SWCNTs, obtained by this route, were used for incorporation into the matrix of the automotive acrylic paint.

2.3. Incorporation of CNT's into the Acrylic Paint. Diverse paint-SWCNTs composites were prepared varying the percentage of incorporated SWCNTs via direct aggregation of nanotubes. The used nomenclature is shown in Table 1.

Applying the experiment design ANOVA (Varianza Analysis) of 3 factors, the experimental scheme indicated in Table 2 was determined. $0.038,0.077,0.20,0.38$, and 0.77 wt. $\%$ of SWCNTs in respect of the paint were used. All experiments 


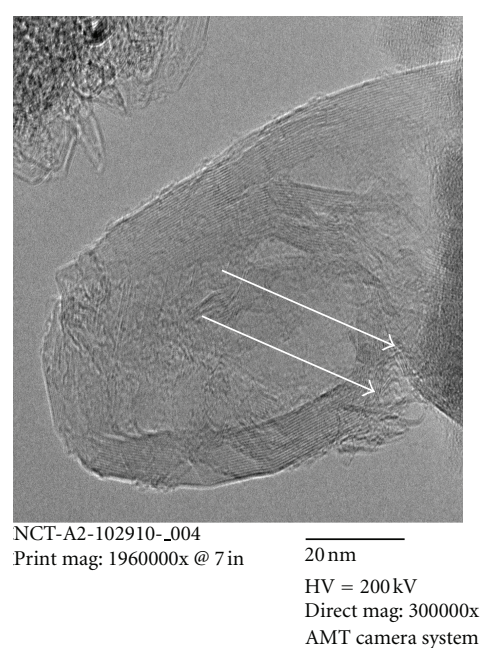

(a)

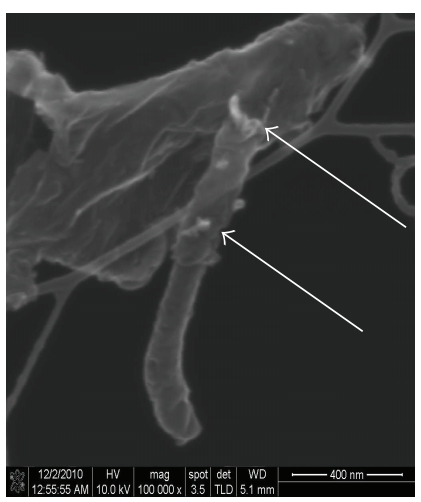

(b)

FIgURE 6: (a) TEM image of the sample of (aminoisophthalic acid)-SWCNTs, (b) SEM image showing interconnections of two nanotubes.

were carried out at r.t. and ambient pressure containing the following steps.

(1) Corresponding quantities of SWCNTs were weighed using recipients de $2 \mathrm{~mL}$.

(2) $0.5 \mathrm{~mL}$ of Tinner (mixture of toluene, xylene, alcohols, and esters) was added and sonicated for $2 \mathrm{~min}$.

(3) $1 \mathrm{~mL}$ of the paint was added and sonicated for $5 \mathrm{~min}$.

(4) Using a pistol connected to the air compressor, the formed composite was applied on the metallic surface (aluminium and steel).

(5) 20 min after the application, the piece was subjected to a thermal treatment for drying at $200^{\circ} \mathrm{C}$ for $5 \mathrm{~h}$ in the oven SL SHELLAB, M: 1400E.

(6) Then, the paint on metallic sheets is subjected to degradation treatment.

The characterization of SWCNTs samples was carried out in electron microscopy equipments TEM and SEM, as well as by Raman spectroscopy. The generated paint-SWCNTs

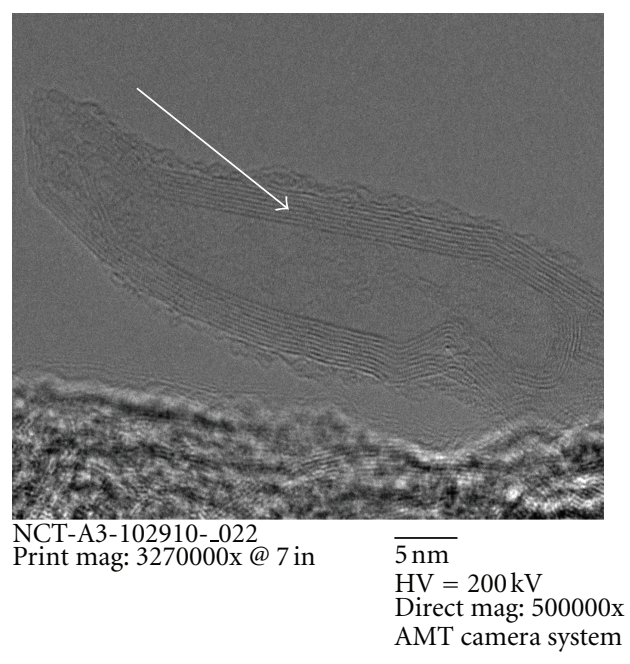

(a)

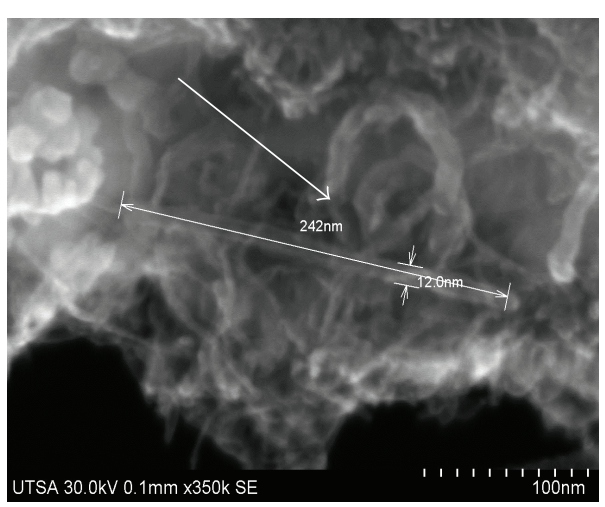

(b)

FIGURE 7: (a) TEM image of $p$-anisidine-SWCNTs, (b) SEM image of the sample, showing the formation of spiral-type rings and arcs.

composites were studied by proofs of thermal dissipation (TRITEC sensor of external temperature Pt1000), thickness, surface morphology (AFM), and by relative degradation by electron flow in SEM (model: FEI Nova NanoSEM 200).

\section{Results and Discussion}

3.1. Analysis of Carbon Nanotubes, Functionalized with Organic Molecules (Aniline-SWCNT's). Figure 5 shows electron microscopy images of 4-aminopyridine-SWCNTs. As a result of functionalization, the unions are formed, which can be used for construction of cross-linkers due to supramolecular interactions of the SWCNTs after being modified with organic molecules.

In case of the SWCNTs, functionalized with aminoisophthalic acid, Figure 6(a) shows the sites, where the carbon nanotube can be connected with another one. This can be used for creation of a larger structural net, which serves as an enforcement for a polymer matrix. The arrows in Figure 6(b) show these sites, appreciated as small protuberances. Evidently, the nanotube reaches to be connected with another 


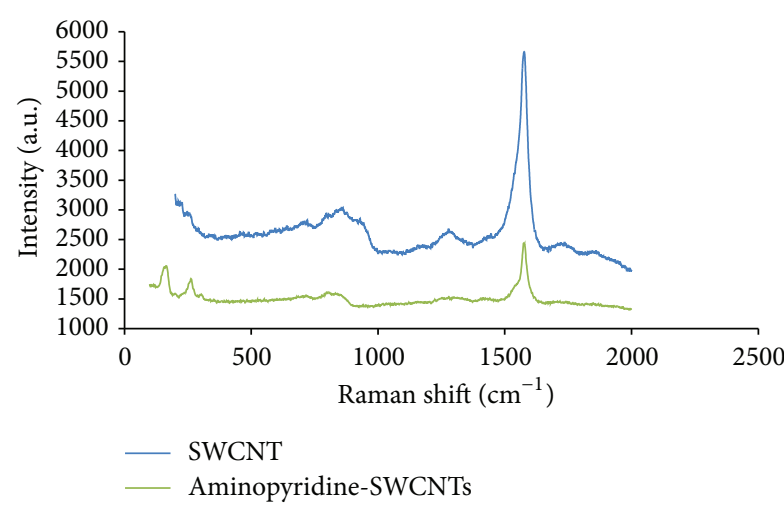

(a)

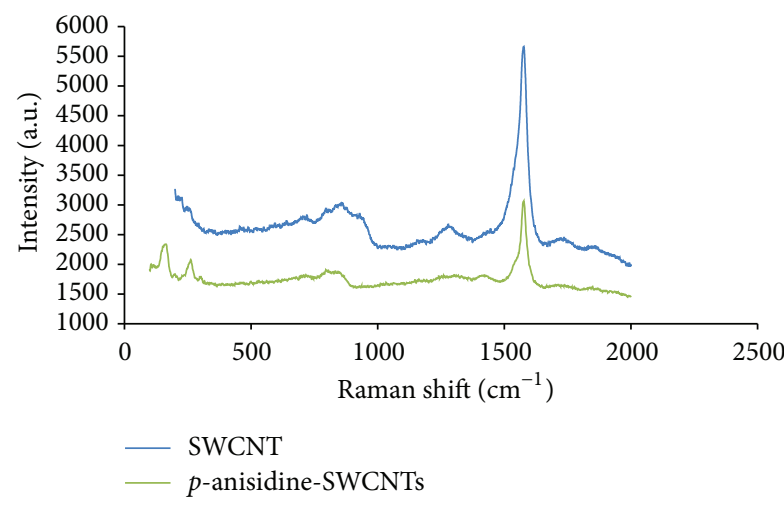

(c)

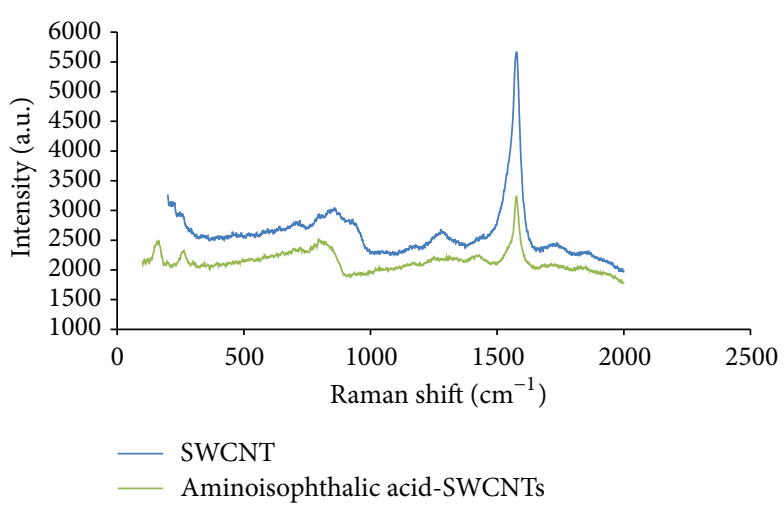

(b)

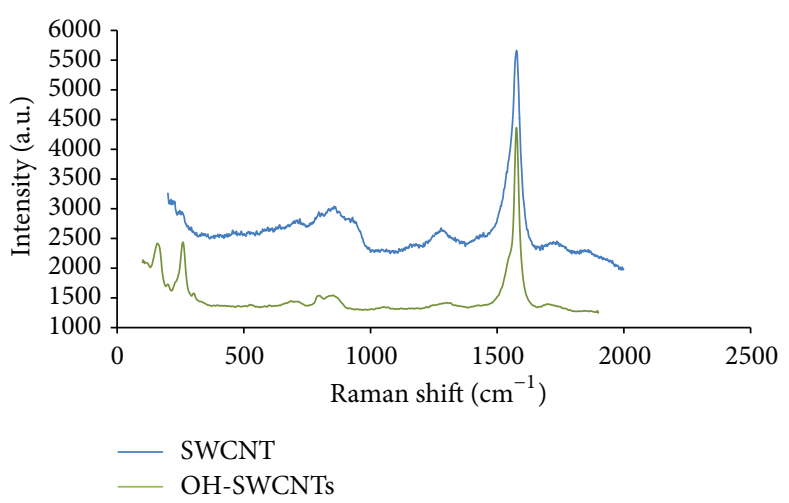

(d)

FIGURE 8: Raman spectroscopy data for: (a) aminopyridine-SWCNTs, (b) (aminoisophthalic acid)-SWCNTs, (c) p-anisidine-SWCNTs, (d) OH-SWCNT.

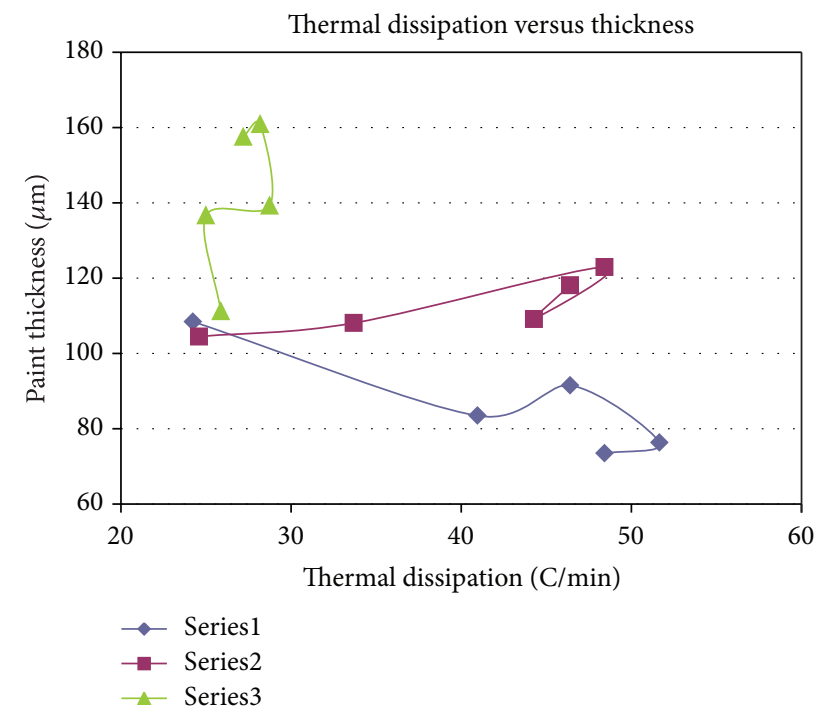

FIGURE 9: Relation between the fastness of thermal dissipation and thickness of the final layer.

one via action of organic molecules added during the functionalization process.

Figure 7(a) shows a TEM image of the simple of $p$ anisidine-SWCNTs and an interaction of two nanotubes, whose result is the formation of a ring. The arrow shows the nanotube surface, where the functionalization takes place. The increase of tension of carbon "lines" on the nanotube surface causes the effect, that the $p$-anisidine-SWCNTs are transformed in ringes and arcs (Figure 7(b)). This tension could be attributed to the methoxy group $\left(-\mathrm{O}-\mathrm{CH}_{3}\right)$ in the benzene ring.

3.2. Raman Spectroscopy Analysis of Functionalized Nanotubes. Figure 8 shows Raman spectroscopy data of the functionalized SWCNTs and the G-band (peak at $\sim 1600 \mathrm{~cm}^{-1}$ ). For all functionalized samples, considerable changes, in comparison with nonfunctionalized SWCNTs, are observed in the ranges of $\sim 200-300 \mathrm{~cm}^{-1}$ and $1250-1370 \mathrm{~cm}^{-1}$.

\subsection{Analysis and Study of Composite Paints after Incorporation} of Carbon Nanotubes. The main observations of composite paints, obtained by aggregation of SWCNTs to the conventional paint, are as follows.

(1) Via a visual inspection, it was determined that the SWCNTs presented a low level of homogenization in the acrylic paint. The color change, attributed to the SWCNTs presence, was practically absent.

(2) The paint composite after incorporation of $\mathrm{OH}$ SWCNTs showed very high particle homogenization 


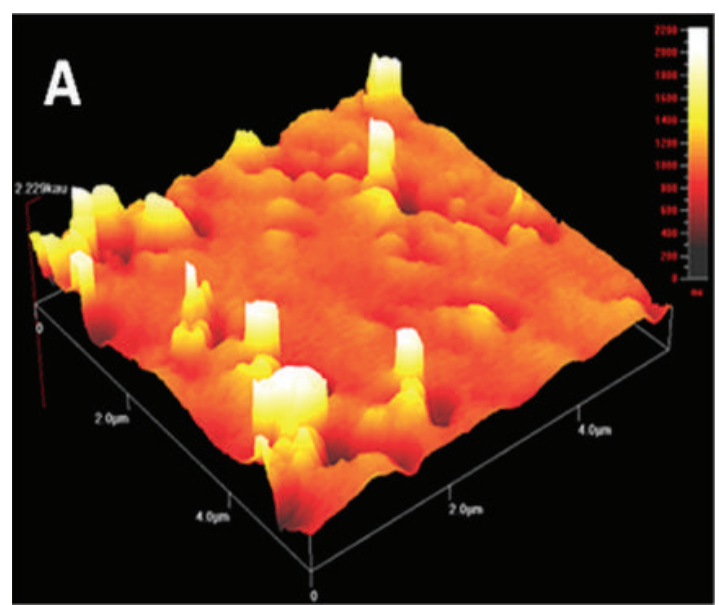

(a)

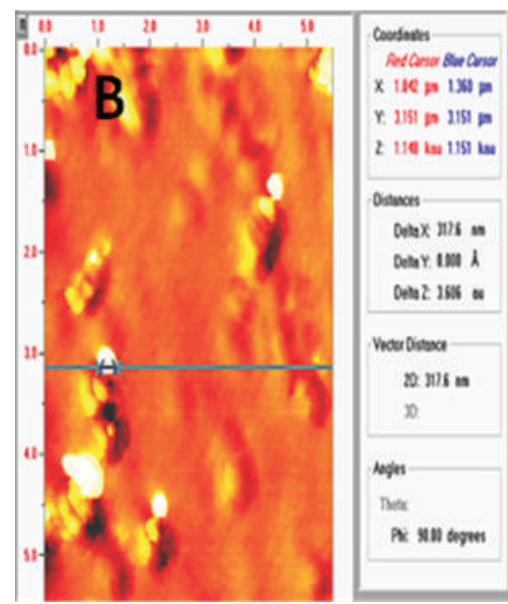

(b)

Figure 10: AFM image of the P1SWFC5: (a) phase mode, (b) the protuberance width is $300 \mathrm{~nm}$, height is $42.96 \mathrm{~nm}$.

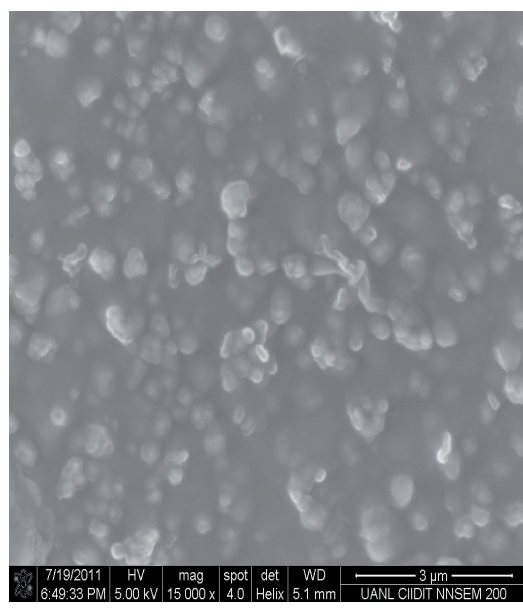

(a)

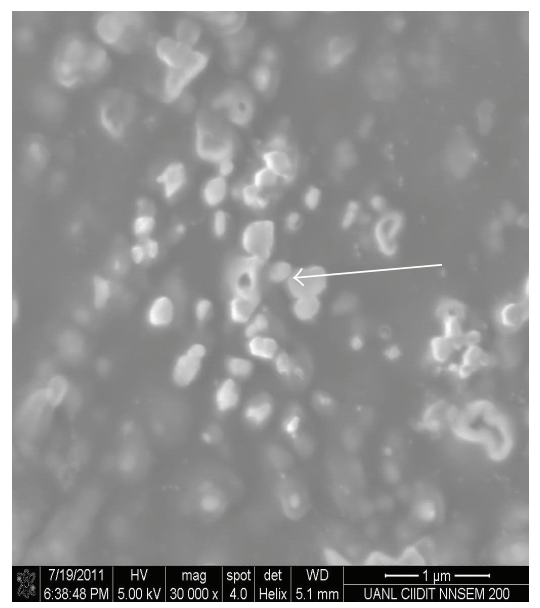

(b)

FIGURE 11: SEM image of the sample P1SWOH4: (a) distribution of nanotubes in the matrix, (b) OH-SWCNTs after degradation of the matrix via electron flow (sample P1SWOH4).

level due to the presence of $\mathrm{OH}$-groups. The composite color was changed from white (original color of the paint) to obscure grey.

(3) High distribution of OH-SWCNTs in the paint matrix increases the capacity of covering material surface of the paint up to $30 \%$. Maintaining the quality of the paint layer, the best results were obtained with incorporation of $\mathrm{OH}$-functionalized carbon nanotubes at 0.38 wt.\%.

(4) In case of incorporation of anisidine-SWCNTs, a high homogenization level was reached, leading to increase of the capacity of covering material surface by the paint up to $30 \%$.

(5) In case of drying process at $200^{\circ} \mathrm{C}$, it was determined that, in case of OH-SWCNTs and anisidine-SWCNTs, the composite paints possess a higher hardness and a rapid dissipation of temperature, compared with the original paint or the paint with incorporated nonfunctionalized nanotubes.

(6) The process of degradation of the paint using the electron flow of $30 \mathrm{kV}$ and evaluation of SEM and AFM images offer a criterion to determine possible changes of the structural morphology, expecting to find better matrix covering $[17,18]$.

3.4. Thickness of the Final Layer. The thickness of the final layer of the formed paint layer using additives of SWCNTs, OH-SWCNTs, and anisidine-SWCNTs are shown in Table 3. The medium magnitudes of 5 experimental data for each sample were calculated.

3.5. Fastness of Thermal Dissipation. The fastness of thermal dissipation was calculated in a temperature range $25 \div$ $180^{\circ} \mathrm{C}$ per minute, approximately (Table 4 and Figure 9). 
The fastest dissipation was found in the paints, whose samples correspond to $\mathrm{P} 1 \mathrm{SWOH}$, for example, the major fastness $51.66^{\circ} \mathrm{C} / \mathrm{min}$ was observed for the sample P1SWOH4.

According to these results, it is recommended for industrial applications to use OH-SWCNTs due to the quality of thickness of the layer and the capacity of thermal dissipation.

3.6. AFM Analysis of the Automotive Paint with SWCNTs Additives (for the Sample of P1SWFC5). The presence of nanocraters can inhibit the process of solar degradation, as well as the size of the protuberances caused by the $\mathrm{OH}$ SWCNTs. The evaluated sample of P1SWFC5 is shown in Figure 10, where the effect of the CNTs on the modification of relief of the paint after its application to a material surface can be appreciated. It is expected that the protuberances impact development of the paint, increasing its life circle.

3.7. SEM Analysis of the Automotive Paint with SWCNTs Additives (for the Sample of P1SWFC4). The aniline group $-\mathrm{NH}_{2}$, incorporated to the SWCNTs surface, possess high polarity and, together with $\mathrm{OH}$ groups, are most common functional groups in the automotive paint [19]. For the samples, treated in the process 1 (heating of the paint, applied to the surface, at $200^{\circ} \mathrm{C}$, dried at $200^{\circ} \mathrm{C}$, the crystal formation was observed, maybe due to the presence of metal oxides. It is known that the automotive paints contain additives of metal oxides in order to improve some paint properties, for instance adherence. The composite of the anisidineSWCNTs, incorporated to the matrix of the paint, was studied by SEM microscopy; the resulting image for the sample P1SWFC4 is shown in Figure 11. It is important to note that, after the degradation via electron flow, the formed crystals and the added anisidine-SWCNTs remain in the sample (the matrix is considerably degraded).

3.8. Relative Degradation via Electron Flow. To evaluate matrix degradation and incorporation of SWCNTs to the paint, the samples were subjected to a related degradation via the electron flow in the SEM microscopy, applying electrons of $30 \mathrm{kV}$. The results are presented in Table 5 .

By incorporation of SWCNTs, the resistance of the resulting composite paint against degradation increases. The effect of the SWCNTs on the resistance of paints against degradation up to $\sim 500 \%$, as it is shown in Figure 12 .

It is important to comment that relative degradation of the composite was carried out in the similar conditions for all samples. As a result of degradation treatments, the SWCNTs are not destroyed by electron flow, in a difference with the polymeric matrix of the paint.

\section{Conclusions}

It was established that via the functionalization of carbon nanotubes with aryl diazonium salts, the molecules with para (4-aminopiridine, $p$-anisidine) and meta (5aminoisophthalic acid) can be used. The presence of methoxy group in the benzene ring in $p$-position leads to the ring

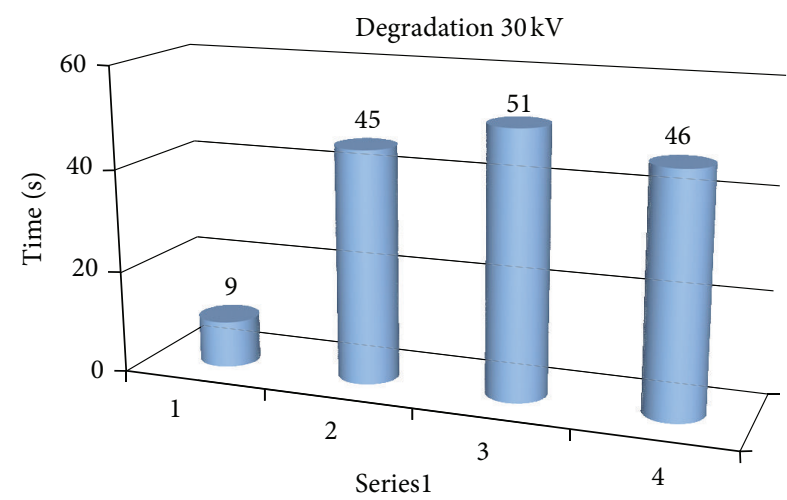

FIGURE 12: Degradation of samples using the electron flow of $30 \mathrm{kV}$.

morphology of the functionalized SWCNTs. These nanostructures can be applied for improvement of automotive paints.

On the basis of dispersion of SWCNTs in an organic solvent, it is possible the incorporation of SWCNTs, OHSWCNTs, and anisidine-SWCNTs in automotive paint matrices. From the industrial point of view, the best properties of the paint are achieved by incorporation of OH-SWCNTs and anisidine-SWCNTs, in comparison with nonfunctionalized SWCNTs or functionalized with other molecules.

The effect of the OH-SWCNTs and anisidine-SWCNTs, being incorporated in a automotive paints, corresponds to the $\sim 500 \%$ higher resistance against degradation by electron flow of $30 \mathrm{kV}$ in comparison with the paint without incorporation of SWCNTs.

The incorporation of SWCNT's modifies the resulting paint color. In case of the OH-SWCNTs, the nanotubes are predominantly accommodated vertically in the paint applied in the surface (Figures 10 and 11).

It has been proved that physical properties of the composite paint can be considerably improved, leading to high capacity of the applied paint (ability to cover surfaces), fastness of thermal dissipation, high homogeneity in the paint matrix and, possibly, high probability of inhibition of solar degradation. The incorporation of $\mathrm{OH}-\mathrm{SWCNTs}$ in the automotive paint was chosen as the best additive to improve its physical properties.

\section{References}

[1] M. J. Rivas Martínez, J. Román Ganzer, and M. L. Cosme Huertas, "Future and current applications of carbon nanotubes, material Iinnovation, aerospace technology and nanotechnology," Technology Watch Report, CIMTAN, INTA, Madrid, Spain, 2007.

[2] M. A. Petrukhina and L. T. Scott, Fragments of Fullerenes and Carbon Nanotubes: Designed Synthesis, Unusual Reactions, and Coordination Chemistry, Wiley, 1st edition, 2011.

[3] P. Harris, Carbon Nanotube Science: Synthesis, Properties and Applications, Cambridge University Press, 2nd edition, 2011.

[4] A. K. Mishra, Carbon Nanotubes: Synthesis and Properties, Nova Science, 2013. 
[5] A. Haghi, Carbon Nanotubes: Properties, Performance and Applications, Gazelle Distribution, 2012.

[6] S. R. Bakshi, D. Lahiri, and A. Agarwal, "Carbon nanotube reinforced metal matrix composites-a review," International Materials Reviews, vol. 55, no. 1, pp. 41-64, 2010.

[7] F.-L. Jin and S.-J. Park, "A review of the preparation and properties of carbon nanotubes-reinforced polymer composites," Carbon Letters, no. 2, pp. 57-69, 2011.

[8] K. Schulte, F. H. Gojny, B. Fiedler, J. K. W. Sandler, and W. Bauhofer, "Carbon nanotube-reinforced polymers: a state of the art review," Polymer Composites, part 1, pp. 3-23, 2005.

[9] M. R. Loos, L. A. F. Coelho, S. H. Pezzin, and S. C. Amico, "Effect of carbon nanotubes addition on the mechanical and thermal properties of epoxy matrices," Materials Research, vol. 11, no. 3, pp. 347-352, 2008.

[10] L. Ci and J. Bai, "The reinforcement role of carbon nanotubes in epoxy composites with different matrix stiffness," Composites Science and Technology, vol. 66, no. 3-4, pp. 599-603, 2006.

[11] S. Kim, L. Chen, J. K. Johnson, and E. Marand, "Polysulfone and functionalized carbon nanotube mixed matrix membranes for gas separation: theory and experiment," Journal of Membrane Science, vol. 294, no. 1-2, pp. 147-158, 2007.

[12] K. Prashantha, J. Soulestin, M. F. Lacrampe, M. Claes, G. Dupin, and P. Krawczak, "Multi-walled carbon nanotube filled polypropylene nanocomposites based on masterbatch route: improvement of dispersion and mechanical properties through PP-g-MA addition," Express Polymer Letters, vol. 2, no. 10, pp. 735-745, 2008.

[13] P. A. Corvillo, Synthesis, photophysical properties and applications of functionalized single wall carbon nanotubes; Valencia [Ph.D. thesis], 2007.

[14] J. J. Stephenson, A. K. Sadana, A. L. Higginbotham, and J. M. Tour, "Highly functionalized and soluble multiwalled carbon nanotubes by reductive alkylation and arylation: the billups reaction," Chemistry of Materials, vol. 18, no. 19, pp. 4658-4661, 2006.

[15] J. J. Stephenson, J. L. Hudson, S. Azad, and J. M. Tour, "Individualized single walled carbon nanotubes from bulk material using 96\% sulfuric acid as solvent," Chemistry of Materials, vol. 18, no. 2, pp. 374-377, 2006.

[16] B. K. Price and J. M. Tour, "Functionalization of single-walled carbon nanotubes 'on water,' Journal of the American Chemical Society, vol. 128, no. 39, pp. 12899-12904, 2006.

[17] S. Wolfe, C. F. Ingold, and R. U. Lemieux, "Oxidation of olefins by potassium permanganate. Mechanism of $\alpha$-ketol formation," Journal of the American Chemical Society, vol. 103, no. 4, pp. 938-939, 1981.

[18] J. L. Li, K. N. Kudin, M. J. McAllister, R. K. Prud'homme, I. A. Aksay, and R. Car, "Oxygen-driven unzipping of graphitic materials," Physical Review Letters, vol. 96, no. 17, Article ID 176101, 4 pages, 2006.

[19] D. G. Weldon, Failure Analysis of Paints and Coatings, John Wiley \& Sons, London, UK, 2009. 

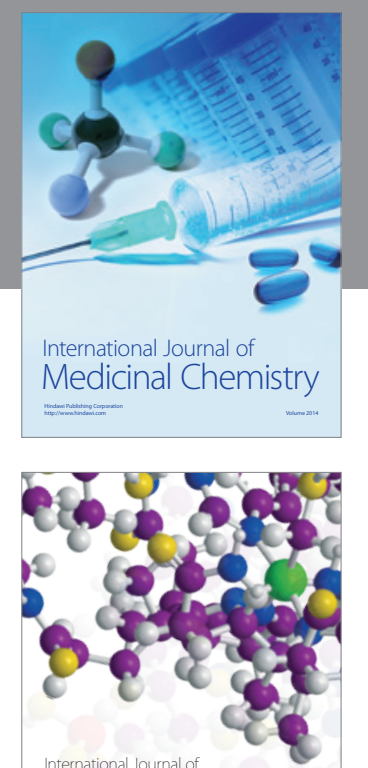

\section{Carbohydrate} Chemistry

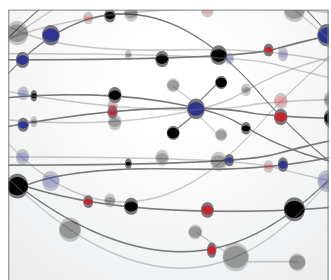

The Scientific World Journal
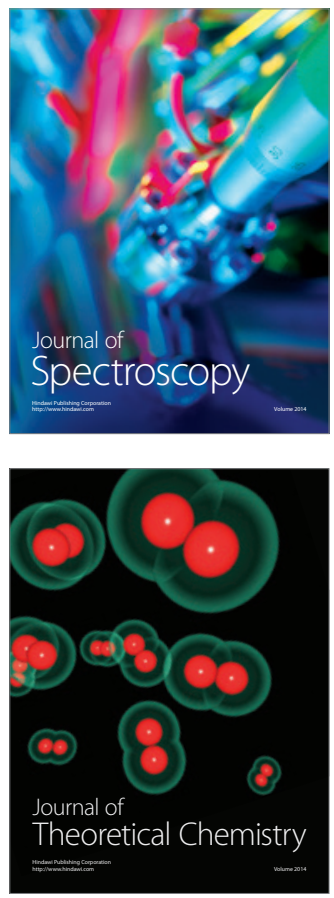
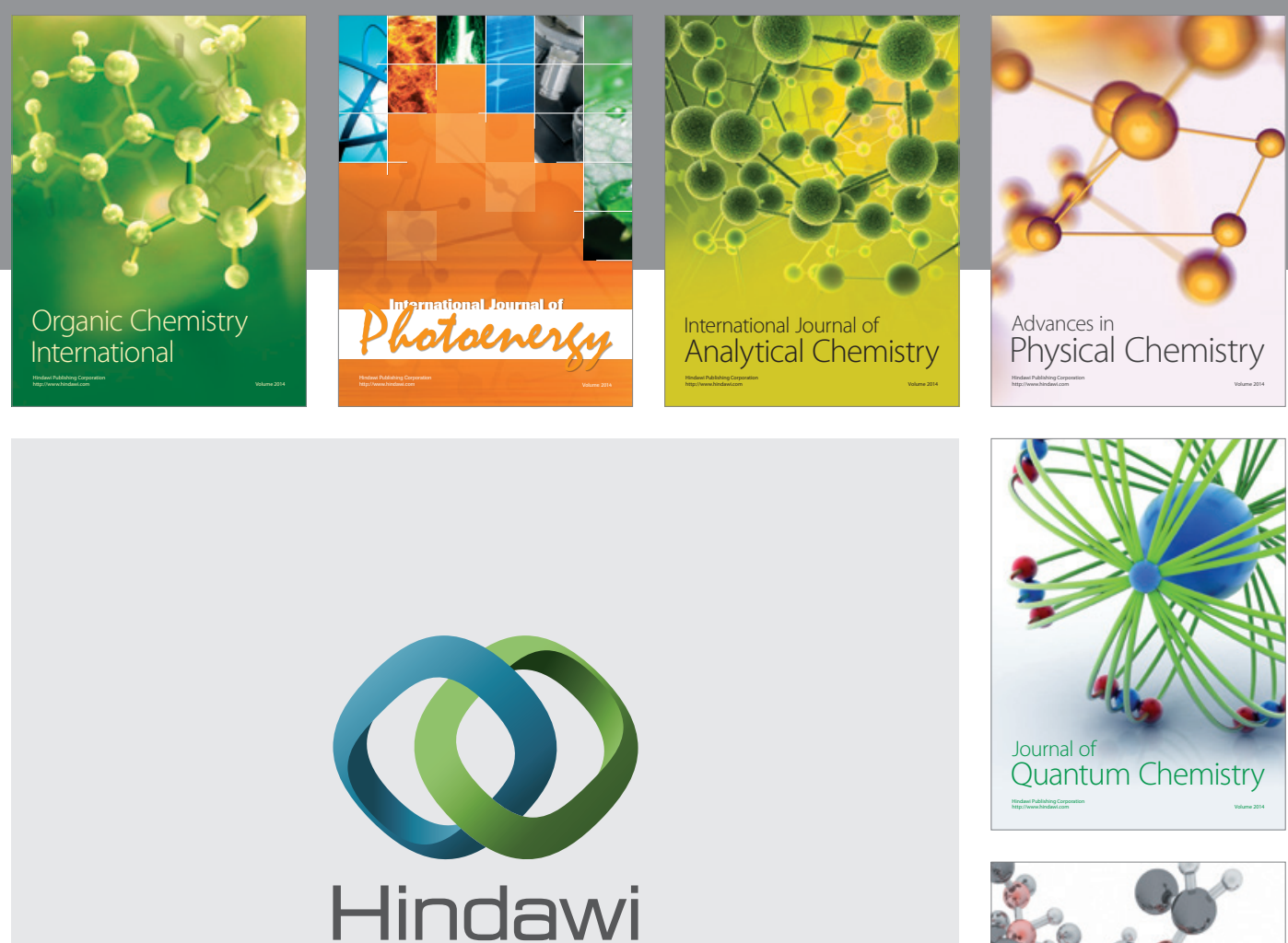

Submit your manuscripts at

http://www.hindawi.com

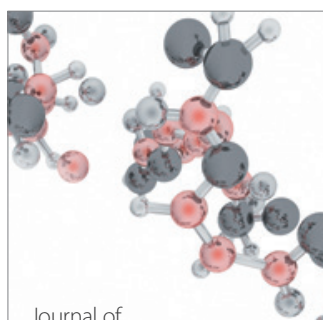

Analytical Methods

in Chemistry

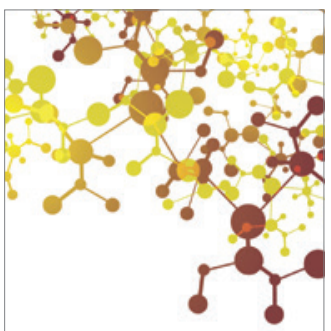

Journal of

Applied Chemistry

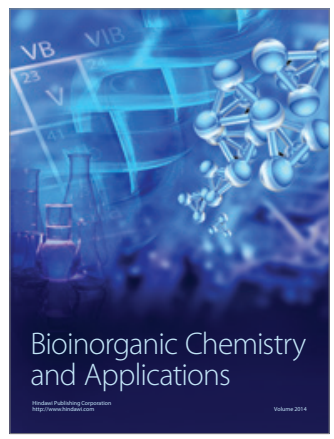

Inorganic Chemistry
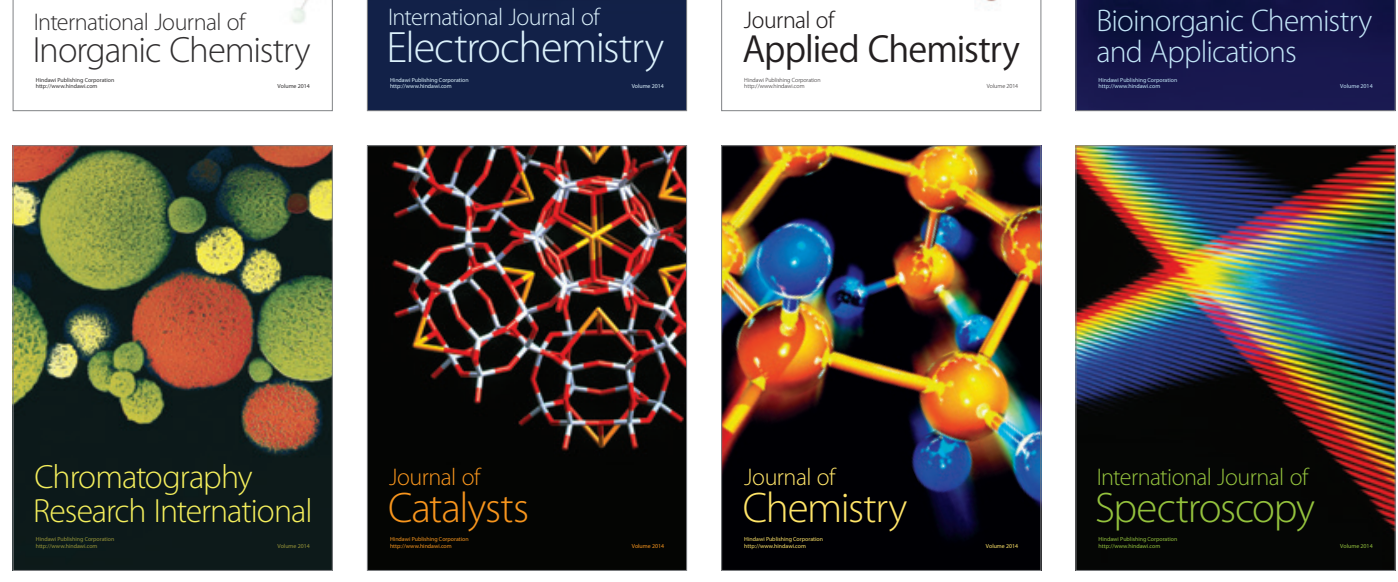